VII Congresso Brasileiro de Informática na Educação (CBIE 2018)

Anais do XXIX Simpósio Brasileiro de Informática na Educação (SBIE 2018)

\title{
PiScrum: o Scrum para disciplinas de Projeto Integrado
}

\author{
Danilo Almeida Felipe, Tânia Saraiva de Melo Pinheiro \\ Campus Quixadá - Universidade Federal do Ceará \\ Av. José de Freitas Queiroz, 5003 - Cedro - Quixadá - Ceará 63902-580 \\ daniloafel@gmail.com, taniapinheiro@ufc.br
}

\begin{abstract}
This study adapted the Scrum framework for Integrated Project classes, meeting the need to manage interdisciplinary and complex projects, developed together with all disciplines of the same semester and dealing with real client problems. Following Action Research, classes were observed, a first proposal was organized and evaluated. The result was the framework PiScrum, already in use in a new class, starting a new refinement cicle.
\end{abstract}

Resumo. Esta pesquisa adaptou o framework Scrum para disciplinas de Projeto Integrado, para se conseguir gerenciar projetos interdisciplinares e complexos, por serem desenvolvidos junto às outras disciplinas do mesmo semestre, e tratar problemas de clientes reais. Seguindo a Pesquisa-Ação, turmas foram observadas, uma primeira proposta foi delineada e aplicada visando sua avaliação. O resultado foi o framework PiScrum, já em uso em nova turma, se iniciando novo ciclo de refinamento desta proposta.

\section{Introdução}

Visando melhorar o gerenciamento de projetos práticos e interdisciplinares desenvolvidos em disciplinas iniciais de Projeto Integrado de um curso de graduação em Design Digital, este estudo teve o objetivo de adaptar, para fins pedagógicos, um dos métodos de gerenciamento de projetos ágil conhecidos na Engenharia de Software [Pressman 2011]: o framework Scrum. Ele foi escolhido por sua popularidade em mercado e por ser alvo de diferentes estudos sobre o ensino de desenvolvimento de software com práticas semelhantes às do mercado de trabalho, como em Meireles e Bonifácio (2015), que aliam a metodologia de Aprendizado Baseado em Problemas com o ensino de Engenharia de Software.

De acordo com a classificação de Felipe e Pinheiro (2018), as disciplinas de Projeto Integrado (PIs) estudadas são do tipo horizontal-curricular-externa, um dos mais difíceis de ser conduzidos por conter, simultaneamente, fatores como: interlocução com disciplinas em paralelo, com o aprendizado de conteúdos ocorrendo com o próprio projeto que dele necessita; obrigatoriedade curricular; e orientação compartilhada com professores externos à disciplina de PI (outros docentes do semestre). Fazendo-se necessário intervir de maneira a suavizar a dificuldade sentida nessas disciplinas, notada tanto pelos professores quanto pelos alunos que a compõem.

As disciplinas de PIs estudadas seguem a pedagogia descrita por Schön (2000) como uma epistemologia da prática baseada na ação-reflexão: em geral, são conduzidas "em torno de projetos gerenciáveis de design, assumidos individual ou coletivamente, mais ou menos padronizados de forma similar a projetos tirados da prática real." [Schön 
VII Congresso Brasileiro de Informática na Educação (CBIE 2018)

Anais do XXIX Simpósio Brasileiro de Informática na Educação (SBIE 2018)

2000]. Esta pesquisa foi guiada pela metodologia Pesquisa-Ação [Thiollent 2004], com uma professora representando os interessados do campo estudado (alunos e demais professores) e o pesquisador fazendo o elo entre a prática observada e a teoria relacionada ao Scrum à pedagogia de Schön (2000), levando à criação do PiScrum.

\section{Metodologia}

A metodologia seguiu princípios da Pesquisa-Ação (PA) que visa gerar conhecimento a partir de ações de caráter social. Thiollent (2004) relaciona alguns possíveis objetivos de conhecimento potencialmente alcançáveis pela pesquisa-ação, dentre os quais destacamse para este trabalho: a) A produção de guias ou de regras práticas para resolver os problemas e planejar as correspondentes ações; b) Os ensinamentos positivos ou negativos quanto à conduta de ação e suas condições de êxito.

$\mathrm{Na} \mathrm{PA}$, o conhecimento novo é construído a partir da relação entre saber informal do campo e o saber formal dos pesquisadores. Nesta pesquisa, uma professora de Projeto Integrado representa o grupo de interessados e o pesquisador corresponde ao especialista que faz a articulação entre a prática observada e a teoria relacionada à gerência de projetos. As atividades gerais realizadas estão descritas na Tabela 1.

Tabela 1. Fases da pesquisa-ação neste trabalho.

\begin{tabular}{|l|l|l|}
\hline \multicolumn{1}{|c|}{$\begin{array}{c}\text { FASES DA PESQUIO } \\
\text { AÇA- }\end{array}$} & \multicolumn{1}{|c|}{ DESCRIçÃo } & \multicolumn{1}{c|}{ REALIZADO } \\
\hline $\begin{array}{l}\text { Fase exploratória. } \\
\text { Formulação do tema. }\end{array}$ & $\begin{array}{l}\text { Definir o campo da pesquisa e o } \\
\text { problema a ser solucionado. }\end{array}$ & $\begin{array}{l}\text { Tema: aplicação de metodologias de gerência de projetos } \\
\text { em turmas de Projeto Integrado. }\end{array}$ \\
\hline Campo de observação. & $\begin{array}{l}\text { Delimitação do campo de estudo e } \\
\text { ação. }\end{array}$ & Turmas de Projeto Integrado I e II. \\
\hline $\begin{array}{l}\text { Colocação dos } \\
\text { problemas. } \\
\text { O lugar da teoria. }\end{array}$ & $\begin{array}{l}\text { Delinear problemas sob uma } \\
\text { perspectiva teórica. }\end{array}$ & $\begin{array}{l}\text { Fase inicial: descrever atividades da disciplina em } \\
\text { consonância ao Scrum, por meio de observação não- } \\
\text { participante em Projeto Integrado Il. }\end{array}$ \\
\hline Seminários. & $\begin{array}{l}\text { Eventos periódicos de planejamento e } \\
\text { avaliação da ação. }\end{array}$ & $\begin{array}{l}\text { Reuniões semanais entre pesquisador e professora } \\
\text { participante para autoavaliação da ação. }\end{array}$ \\
\hline Hipóteses. & Hipótese de solução. & $\begin{array}{l}\text { Seria necessário adaptar o Scrum, incluindo: a) fazer uma } \\
\text { primeira; b) incluir Scrum no planejamento da disciplina. }\end{array}$ \\
\hline $\begin{array}{l}\text { Coleta de dados. } \\
\text { Aprendizagem. Plano de } \\
\text { ação. }\end{array}$ & $\begin{array}{l}\text { Coleta de Dados que retroalimenta o o } \\
\text { planejamento da ação. }\end{array}$ & $\begin{array}{l}\text { Aplicar o Scrum em PI, com autoavaliação semanal com } \\
\text { professora representando o campo da pesquisa, visando } \\
\text { retroalimentação da ação. }\end{array}$ \\
\hline $\begin{array}{l}\text { Saber formal e saber } \\
\text { informal. }\end{array}$ & $\begin{array}{l}\text { Articulação do saberformal e saber } \\
\text { informal do participante. }\end{array}$ & $\begin{array}{l}\text { Modelagem final do Scrum para as disciplinas de Projeto } \\
\text { Integrado. }\end{array}$ \\
\hline Divulgação externa. & - & Publicação em monografia e conferências. \\
\hline
\end{tabular}

A primeira coluna da Tabela 1 relaciona as fases ou temas gerais da PesquisaAção e a segunda coluna uma descrição considerando o contexto de aplicação neste trabalho. A terceira coluna descreve o que foi realizado neste estudo.

\section{PiScrum}

O framework PiScrum elaborado é adaptação do Scrum específica para as disciplinas de PI estudadas, conciliando dois focos: desenvolvimento de produtos, como no Scrum; e aprendizado, como no eduScrum, uma versão do Scrum com fins educacionais [Delhij et al. 2016]. Os dois foram necessários porque, em PI, se tem tanto conteúdos de aprendizagem (eduScrum) como a elaboração de projetos que lidam com a concepção 
VII Congresso Brasileiro de Informática na Educação (CBIE 2018)

Anais do XXIX Simpósio Brasileiro de Informática na Educação (SBIE 2018)

de produtos de software utilizáveis (websites responsivos, aplicativos móveis, dentre outros), denominados como entregáveis (Scrum).

O PiScrum adota os mesmos pilares que seus guias-base Scrum e eduScrum, descritos a seguir já com considerações relacionadas ao seu uso em PIs: Transparência, relacionada às características do processo serem conhecidas pelos envolvidos, demandando do professor uma boa especificação das atividades discentes e critérios de avaliação dos projetos, bem como do que será desenvolvido na disciplina em consonância com as disciplinas em paralelo; a Inspeção, que prevê que envolvidos constantemente verifiquem o progresso do projeto, o que, no PiScrum, condiz com o uso de armazenamento de arquivos e ferramenta online de gerenciamento de projetos para acompanhamento, o que agrega a possibilidade de mediação docente online; a Adaptação aborda que ajustes no processo devem ser realizados o mais rapidamente quando notadas divergências em relação ao esperado, o que, no PiScrum, orienta o docente a fornecer feedbacks frequentes aos projetos, melhorando a qualidade na perspectiva de aprendizado do aluno e no produto desenvolvido em cada projeto.

De forma semelhante, o PiScrum estabelece um processo de desenvolvimento iterativo e incremental, times auto-organizáveis e o trabalho em Papéis, Artefatos e Cerimônias. Os papéis são Product Owner, Scrum Master e Equipe de desenvolvimento. O Product Owner é o papel do representante dos stakeholders de um produto, responsável por especificar e priorizar o que será desenvolvido, além de fornecer feedbacks e orientações. Apesar de se ter clientes de campo reais nos PIs, esse papel é representado pelo professor, por ser quem, em última instância, define entregáveis para a disciplina e suas priorizações, além de ser o responsável pelo aprendizado.

O Scrum Master é um papel assumido inicialmente também pelo professor, que repassa a responsabilidade gradualmente a um aluno de cada equipe, o qual passa a ser o responsável por garantir a ocorrência de cerimônias, regras e práticas do PiScrum, manter os artefatos atualizados e mediar possíveis conflitos. Essa escolha deve-se ao fato de que, o aluno, como aprendiz, não tem maturidade suficiente para receber e entender responsabilidades inicialmente de uma só vez.

Por fim, a Equipe de Desenvolvimento é um grupo (equipe de alunos) que trabalha na construção de um produto. O Scrum recomenda de quatro a oito pessoas mas, em PIs a experiência recomenda de quatro a cinco. Um importante aspecto do PiScrum é que as equipes não são compostas por especialistas, mas por alunos que adquirem os conhecimentos necessários somente durante o andamento dos próprios projetos, nas disciplinas cursadas em paralelo, o que amplia significativamente a complexidade do trabalho. O Product Owner não é contado como membro de cada time PiScrum, e serve igualmente a todas as equipes.

Sobre os Artefatos, estes são: o Product Backlog, lista de todos os requisitos já identificados pelo Product Owner que, no PiScrum, equivale a todos os entregáveis da disciplina, os quais representam requisitos de aprendizagem exigidos; e o Sprint Backlog, com os itens selecionados para o ciclo de trabalho vigente (Sprint). Ambos os artefatos estão em constante evolução pelo Product Owner e times PiScrum.

Por fim, o PiScrum define cinco Cerimônias: Sprints, Reuniões de Planejamento, Reunião Diária, Revisão da Sprint e Retrospectiva da Sprint. Sprints são 
VII Congresso Brasileiro de Informática na Educação (CBIE 2018)

Anais do XXIX Simpósio Brasileiro de Informática na Educação (SBIE 2018)

"ciclos" de tempo pré-determinados em que todo o trabalho é realizado, e correspondem a um período de três semanas estabelecido por observações da prática em sala de aula; dentro delas, tem-se as demais cerimônias. As Reuniões de Planejamento ocorrem no início de cada Sprint para se definir e detalhar o Sprint Backlog do ciclo vigente; na construção do PiScrum verificou-se que, para serem eficazes, elas deveriam ocorrer em tempo de sala de aula. No Scrum, a Reunião Diária ocorre a cada dia de trabalho, com duração de até quinze minutos para verificação de andamento do trabalho e impedimentos; seu equivalente no PiScrum é fixar pelo menos um horário semanal extra-classe para cada equipe trabalhar em seus projetos, que deve ser iniciado com a verificação prevista pela Reunião Diária.

Finalizando o período da Sprint, há uma apresentação pública, a Revisão da Sprint, uma reunião informal para apresentar a evolução do produto aos stakeholders, visando obter feedback. O PiScrum formalizou-a como os seminários que já ocorriam ao final de cada ciclo incremental de trabalho. Conta com a presença dos professores de PI e de disciplinas paralelas, e eventualmente de stakeholders. Encerrada a Revisão, a Retrospectiva da Sprint é a cerimônia de autoavaliação do time PiScrum, para discussão e implantação de melhorias no processo, que no PiScrum deve ocorrer na primeira reunião extra-classe de cada equipe após a Revisão da Sprint. O Product Owner (o professor) não participa dessa cerimônia.

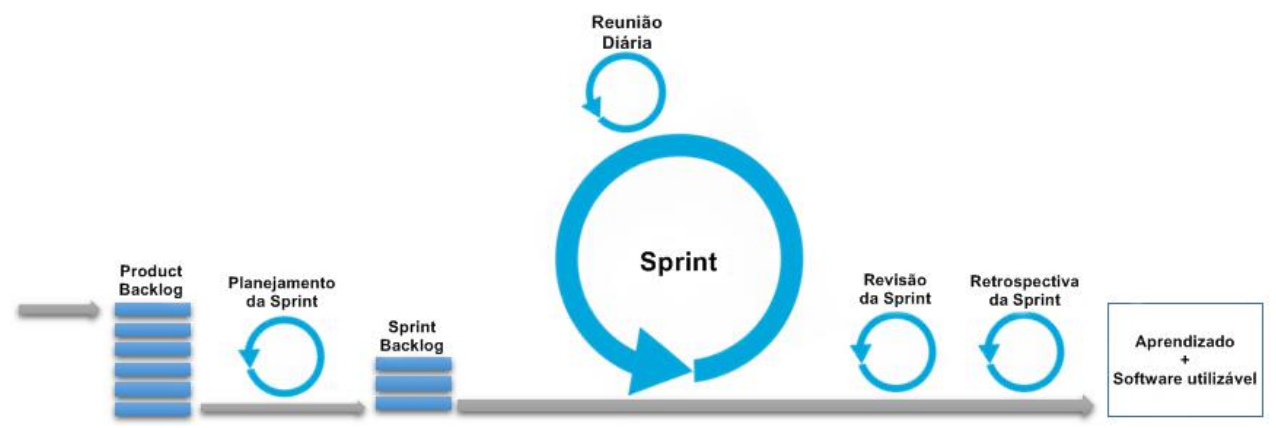

Figura 1. Ciclo de vida do PiScrum (adaptado de sitecampus.com.br)

Em síntese, o PiScrum está ilustrado na Figura 1, um ciclo de vida iterativo e incremental, que começa ao início de um semestre letivo de uma disciplina de PI e tem fim na conclusão do semestre referido. Em cada ciclo, elaboram-se produtos de software utilizáveis por clientes em potencial encontrados em pesquisas de campo. Também considera-se aqui a preparação do aluno em trabalhar com um framework como o PiScrum, possuindo referenciais vindos do Scrum e eduScrum e de amplo estudo de campo realizado com a metodologia Pesquisa-Ação. Espera-se, como consequência, uma melhor preparação do aluno para futuras circunstâncias de sua vida profissional.

\section{Desafios}

Na concepção do PiScrum como uma estrutura para desenvolvimento de produtos e de aprendizado houveram dificuldades peculiares, principalmente devido à tipologia horizontal-curricular-externa em que as disciplinas de PI se encaixam segundo a classificação de Felipe e Pinheiro (2018), realmente sentidas em seu ambiente.

$\mathrm{Na}$ adaptação foi difícil saber como atribuir com o papel do Product Owner, por exemplo. Haviam algumas possibilidades: o cliente de campo, o(s) professor(es) da(s) 
VII Congresso Brasileiro de Informática na Educação (CBIE 2018)

Anais do XXIX Simpósio Brasileiro de Informática na Educação (SBIE 2018)

disciplina(s) ou algum aluno de cada equipe. Para o cliente de campo seria complexo cada time PiScrum estabelecer um canal de comunicação estável com ele, e trazê-lo para a universidade seria um desafio; já o professor não seria capaz de representar interesses do cliente de campo pelo mesmo motivo e ainda lidar com requisitos de aprendizagem; para um aluno de cada equipe seria uma carga cognitiva grande, além das incertezas que poderiam ser geradas ao se representar o desejo do(s) professor(es) e do cliente do campo, necessitando alguma maturidade dele de ser responsabilizado com essa "carga". Optou-se por definir o professor de PI como Product Owner por ser quem, em última instância, decide o que é ou não aceitável para os projetos.

Outra dificuldade sentida foi em estabelecer sincronização de conteúdos entre todas as disciplinas que envolvem os PIs, sendo necessária uma organização prévia em conjunto com todos os professores alocados para que não sejam geradas redundâncias e inconsistências de objetivos, e que se consiga tornar a interdisciplinaridade efetiva.

\section{Considerações Finais}

O PiScrum permitiu que se tivesse mais clareza não apenas quanto à forma de se conduzir os PIs, mas também quanto à metodologia de projeto sendo utilizada. Como resultado, também se conseguiu organizar um processo próprio de produtos digitais/ de software, denominado $\mathrm{PD}_{3}$, e descrito em Pinheiro et al. (2018).

Este estudo é fruto de uma problemática identificada a partir do primeiro semestre de 2017, que motivou a elaboração do PiScrum ao longo dos dois semestres letivos seguintes, e detalhado em Felipe (2018). A oferta contínua de PI I, alternada com PI II, possibilita seu o refinamento contínuo. No segundo semestre de 2018, o PiScrum está novamente sendo aplicado, iniciando-se um novo ciclo de refinamento da proposta.

\section{Referências}

Delhij, A. et al. (2016), “O guia eduScrum”, https://goo.gl/9ui6Tk, October 2017.

Felipe, D.A. (2018), "Adaptação do framework Scrum em disciplinas iniciais de Projeto Integrado”. Monografia. Campus Quixadá, Universidade Federal do Ceará.

Felipe, D.A. e Pinheiro, T.S.M. (2018), "Seleção de tecnologias digitais para a gerência de projetos em disciplinas de projeto integrado", In: \#Tear - Revista de Educação, Ciência e Tecnologia, Canoas, v. 7, n. 1, p. 1-21.

Meireles, M.A.C. e Bonifácio, B.A. (2015), "Uso de Métodos Ágeis e Aprendizagem Baseada em Problema no Ensino de Engenharia de Software: Um Relato de Experiência”. In: XXVI Simpósio Brasileiro de Informática na Educação.

Pressman, R.S. (2011), Engenharia de Software: uma abordagem profissional, Bookman.

Schön, D.A. (2000), Educando o profissional reflexivo, Artmed, $1^{\text {th }}$ ed.

Pinheiro, T.S.M.; Monteiro, I.T.; Felipe, D.A.; Sampaio, A.L. (2018), "O Processo de Design Digital: endereçando o desafio da multidisciplinaridade". In: HCI Education Workshop - Brazilian Symposium on Human Factors in Computing System.

Thiollent, M. (2004), Metodologia da pesquisa-ação, Papirus, $6^{\text {th }}$ ed. 